\title{
Ética española reciente
}

\section{AUGUSTO KLAPPENBACH}

I,B. Vicente Aleixandre

A pesar de la muerte anunciada de la Filosofía en general y de la Ética normativa en particular, ambas siguen gozando de buena salud. Tan buena, al menos, como lo permite una época en la cual el fragmento prima sobre el sistema y el ensayo sobre el tratado. Porque una de las características de esa confusa amalgama de fenómenos que ha dado en llamarse "posmodernidad" consiste en anunciar la "muerte y el "final' de casi todo: de la historia, de los metarrelatos, de las ideologías, de la razón, del sujeto y -cómo no- de la ética. Alguna razón tiene ese anuncio, desde luego. Nuestra época está lejos de aquellas que Comte llamaría «orgánicas", y el búho de Minerva buscaría en vano un paisaje unificado que describir. Pero de ahí a suprimir por decreto esa vieja necesidad humana de dar razón dcl mundo en que se vive, hay un largo trecho. El «pensamiento fuerte" se resiste a morir o al menos a disolverse en acuerdos y conversaciones fluctuantes y circunstanciales como quieren los representantes de esa ética light que nos invade. $Y$ en este sentido hay que celebrar la aparición, en la última Filosofía española, de varios intentos de fundamentación de la experiencia moral que no renuncian al empeño de pensar seriamente, aun sabiendo que el tema tratado siempre supera toda capacidad de interpretación.

En las páginas que siguen nos vamos a limitar a comentar unos pocos libros de reciente aparición en España, sin ninguna pretensión de ofrecer un panorama completo de la Filosofía moral en nuestro ámbito. Dejamos a un lado, en- tre otras, las aportaciones situadas en la línea del «egoísmo racional», más o menos afines a tendencias posmodernas inspiradas frecuentemente en una lectura muy selectiva de Nietzsche. ${ }^{1}$ Nos interesa más - asumiendo los inevitables prejuicios que toda elección supone- el comentario de algunos autores que quizás puedan ser acusados de metafísicos, tal vez por seguir buscando criterios racionales de fundamentación (que no hay que confundir con criterios fundamentalistas). En cualquier caso, y como decía Javier Muguerza, «tal vez un poco de metafísica al año no haga dañon. ${ }^{2}$

La evolución del pensamiento del profesor Aranguren constituye en sí misma un buen resumen del destino que ha sufrido la metafísica en la reflexión moral de las últimas décadas. Quizás esta evolución sea uno de los factores que explique -junto con su talante personal- la enorme influencia que su persona y su obra han tenido y siguen teniendo en el pensamiento español. En el libro de Enrique Bonete, Aranguren: la ética entre la religión y la política, ${ }^{3}$ se intenta -quizás por primera vez- describir esta evolución de modo sistemático y atendiendo al conjunto de su obra. Aranguren ha pasado de sus afirmaciones iniciales acerca de la necesidad que tiene la ética de un fundamento metafísico, en concreto de Dios como inevitable sustentación de todo contenido éti$\mathrm{Co}^{4}$ a posiciones menos dogmáticas y más flexibles pero que no renuncian, como él mismo señala en el epílogo del libro citado, a la utopía y la esperanza. ${ }^{5}$

¿Se reduce esta evolución a un proceso de secularización en el que Dios es 
sustituido por un equivalente más o menos laico pero igualmente fundante? Sin conocer en profundidad el pensamiento de Axanguren nos atrevemos a suponer que no. $Y$ en cualquier caso, creemos que la respuesta a esta pregunta es decisiva para la filosofía moral en los tiempos que corren. Para decirlo en pocas palabras: si la ética continúa necesitando un fundamento metafísico previo se pone en peligro la radicalidad de la experiencia moral; si, por el contrario, la metafísica se concibe como prolongación de esa experiencia, como apertura a una utopia y una esperanza que la moralidad postula pero de la cual no depende, entramos en un terreno de creencias (como el propio Aranguren señala cn el párrafo antes citado) que no pone en cuestión lo que a nuestro juicio constituye la nota especifica de la experiencia moral: su carácter autofundante.

Se habrá advertido que estamos aludiendo a Kant. La "revolución copemicanas que él realiza en el ámbito de la razón práctica (no menos radical que la que propone para la razón especulativa) consiste precisamente en poner la metafísica no antes sino después de la experiencia moral, ese "hecho de la razón* que no necesita de ninguna justificación porque se justifica a sí mismo. La metafísica así entendida continúa siendo discutible - no compartimos personalmente sus postulados acerca de Dios y la inmortalidad- pero no pone a la experiencia ética en función de un neutrum que relativice las relaciones sociales concretas, verdadero "lugar" de la moral, desvirtuando así su radicalidad. Desde este punto de vista, creemos que el pensamiento último de Aranguren no se distancia tanto del enfoque kantiano como podrían hacer suponer sus anteriores críticas a la ética formal. Aunque, por supuesto, será él quien pueda decirlo...

Y ya que estamos con Kant, merece la pena citar el libro de Adela Cortina, Ética sin moral. Asistimos, también en nuestro medio, a una vuelta a la filosofia moral kantiana, probablemente como reacción contra la disolución de la moral en derecho, política y juegos de lenguaje más o menos triviales. La ética, como dice A. Cortina, se está quedando sin moral después de haber perdido sus supuestos como la metafísica y la religión. La vuelta a Kant implica una recuperación de la "ética fuerte», aunque se le reproche un excesivo abstraccionismo y formalismo. Para superarlo, se busca el auxilio de una pragmática del lenguaje que convierta "la universalidad propuesta en procedimental y no meramente formals.?

Siguiendo la línea de la pragmática universal de Habermas y la trascendental de Apel (nos atreveríamos a decir que mejorándola en claridad y precisión) Adela Cortina trata de buscar en los actos de habla los fundamentos de racionalidad, de universalidad y de exigibilidad que permitan recuperar el proyecto ético moderno, desviado de sus exigencias originarias por posmodernos y neoconservadores. El mero hecho de hablar (o al menos de argumentar) implicaría pragmáticamente la afirmación de normas éticas que trascienden (isiempre la metafísica!) la situación concreta de los hablantes y acceden a la universalidad.

Como en el pensamiento de Kant, en el cual se inspira, esta ética de la acción comunicativa busca su fundamento en la misma experiencia ética, convertida ahora en experiencia dialógica. Nos podemos preguntar, sin embargo, si no era preferible la escueta afirmación kantiana del "hecho de la razón» a sus nuevas versiones comunicativas. La formulación de Kant dejaba bien claro el carácter irreductible y último que tienen las relaciones humanas: el otro es un "fin en sí" por el mero hecho de ser 
hombre, sin que se le exija otro requisito que su mera existencia. Las éticas de la comunicación ponen el acento, por el contrario, en el diálogo entendido desde una «comunidad ideal de comunicación" contrafácticamente presente en los actos de habla. Nos tememos que este punto de vista está suponiendo una simetría entre los hablantes que sin duda resulta afirmada pragmáticamente en muchos tipos de discurso, pero no parece tan claro que pueda justificar la universalidad que pretende. Existen muchos «juegos de lenguaje», y no parece evidente que el acuerdo y el consenso constituyan el horizonte de todos ellos. Extender a todos los seres humanos capaces de comunicación lingüistica un acuerdo en los principios éticos fundamentales parece una generalización excesiva.

Y sobre todo, nos tememos que cstas éticas de la comunicación, pese a sus intenciones honestamente universalistas, puedan reforzar una filosofía moral cuyos supucstos se limitan a los participantes efectivos en la acción comunicativa, a quienes de hecho pueden argumentar y comunicarse. No creemos que este enfoque de la experiencia moral sea capaz de dar una respuesta adecuada al problema que, a nuestro juicio, es uno de los más graves con que se enfrenta la ética de nuestros tiempos: la reducción de la moral al ámbito privado y local, el establecimiento de reglas válidas sólo para una parte de la humanidad, aquella que de un modo u otro es capaz de sentarse a la mesa de negociaciones y hacerse oir. Adela Cortina afirma -cuestionando a Rorty - que en su enfoque "la solidaridad cobra vuelos universalistas, en la medida en que se extiende por principio a todo hablante competentew. ${ }^{8}$ Sin poner en duda esta intención, no parece tan claro que las éticas comunicativas escapen a las limitaciones que la autora atribuye, con ra- zón, al pragmatismo norteamericano: establecer una ética construida a la medida de las sociedades democráticas desarrolladas, más adecuada para hacer frente a una discusión parlamentaria que al problema del hambre en Africa. ¿No resulta más clara la categórica afirmación kantiana del hombre como "fin independiente" "contra el que no puede obrarse en ningín casom que esta vaga "comunidad ideal de comunicación", tan alejada de las leyes reales que rigen las relaciones internacionales? Quizás el mérito de Kant haya consistido en subrayar el carácter de "factum" que tiene toda experiencia moral, irreductible a cualquier demostración especulativa y sin embargo capaz de erigirse en criterio último de juicio por el que debe regirse la razón instrumental. Tal vez este sea el límite de las posibilidades de la razón ante la expcriencia moral, y la honestidad de la crítica kantiana consista en no intentar disimularlo.

El excesivo cognitivismo de estas éticas que siguen la línea de Apel y Habermas es uno de los aspectos que critica José Rubio Carracedo en una serie de ensayos publicados bajo el título de Ética constructiva y autonomía personal." A su juicio, la desmedida pretensión de establecer normas universales que impliquen el reconocimiento de "todos" los afectados pone en peligro un aspecto que sus trabajos se preocupan especialmente en destacar: el pluralismo ético, con la consiguiente insistencia en la decisión personal del sujeto autónomo. Su postura, sin embargo, no abandona el programa ético de la modernidad ni renuncia a las fundamentaciones cognitivas: trata de encontrar una sintesis entre la deliberación judicativa (al estilo de Habermas) y los enfoques que acentúan más el momento decisorio (el modo de Tugendhat). Y lo hace insistiendo en un tercer momento: «la elección personal del sujeto, con el consi- 
guiente compromiso individual y existencial" ," que abre la puerta a un legitimo pluralismo en las concreciones prácticas que no se opone a la universalidad de las normas. La ética resulta así uconstructivan, en la medida en que «la autonomía del sujeto moral no viene dada, sino que ha de construirsen."

Se pone así de relieve un aspecto que las éticas comunicativas soslayan: la moral no es sólo una cuestión de acuerdos y consensos sino también de desacuerdos y disidencias. La excesiva insistencia en la formulación kantiana del imperativo categórico «de la universalidad" ha hecho descuidar muchas veces la no menos importante expresión de la persona como "fin on sí; Javier Muguerza ha llamado a esta segunda formulación de Kant wel imperativo de la disidencia», en el sentido de que considera a la persona como un "fin independiente" cuya inviolabilidad le otorga el derecho de decir "no" a cualquier intento de sacrificar al sujeto moral a una ley general que contradiga su dignidad personal autónoma. ${ }^{12}$ Podríamos recordar aquí la expresión de Levinas, cuando habla de la "resistencia ética" que se manifiesta en la relación social como afirmación de la alteridad, aun cuando su enfoque se distancia del formalismo kantiano.13 En cualquier caso, $y$ sin entrar a considerar importantes diferencias de enfoque, parece oportuna esta insistencia en la imposibilidad de subsumir al sujeto moral bajo una norma general, aunque haya que reconocer que las éticas de la comunicación también se han preocupado de este aspecto.

Los trabajos de Rubio Carracedo reunidos en el volumen que comentamos se esfuerzan por compaginar muchas cosas: el consenso con el disenso, la universalidad con la decisión personal, las éticas de convicción con las de responsabilidad, la democracia como sistema político y como forma de vida, el pluralismo y el rechazo al relativismo. Probablemente toda reflexión ética seria, que no acuda al fácil recurso de eliminar por decreto uno de los polos de estas alternativas, se enfrenta con estos problemas. Pero una vez terminada la lectura, uno no puede dejar de preguntarse si esta sintesis resulta posible, aun cuando resulte inevitable el intento de realizarla. La vieja metafísica ya no cumple ni puede cumplir su papel de fundamento del orden moral, asegurando de antemano la superación de todas las antinomias. Pero quicnes se niegan -nos negamos - a reemplazarla por las posmodernidades al uso se encuentran con una difícil situación: por una parte, saben que no pueden recumir a un orden moral previamente dado; por otra, cada vez que pretenden superar la contingencia del sujeto empírico se encuentran abocados a problemas literalmente meta-físicos, como el viejo tema de la universalidad, decisivo para una ética que no se resigne a cumplir un papel puramente descriptivo. Probablemente esta tensión no resuelta sea constitutiva de la ética: resulta mucho más cómodo optar por un pragmatismo más o menos relativista, por un hedonismo individualista o por un egoísmo racional que hacerse cargo de todas las dimensiones a veces contrapuestas que incluye el "hecho de la razón práctica". Por eso deciamos antes que quizás Kant, perplejo ante este límite, se empeño en subrayar el carácter irreductible de la experiencia moral a toda justificación especulativa.

Ni siquiera los representantes de la «ética teológica" se libran de esta tensión. Marciano Vidal ha recopilado cuarenta y cuatro ensayos de autores distintos bajo el título Conceptos fundamentales de ética teologica. ${ }^{14}$ El libro pretende presentar "los planteamientos de la ética cristiana no propuestos, como es habitual, de forma "confesional" o 
marcadamente "ortodoxa" sino presentados críticamente dentro del debate ético públicon. ${ }^{15}$ Es decir, atreviéndonos a traducir estas palabras al hilo conductor que estamos siguiendo en este comentario, sin utilizar las creencias religiosas como fundamentos metafísicos dados sino considerando al cristianismo como una forma de vida o un ethos que no rehúsa someterse a una crítica pública.

Desde luego, no hay nada que objetar a la honestidad intelectual de una ética cristiana así entendida. Toda reflexión ética, y no sólo la cristiana, se realiza desde un determinado ethos, desde supuestos e incluso prejuicios anteriores a cualquier formulación teórica, como Nietzsche se encargo de mostrar cumplidamente. La peligrosidad de los prejuicios no radica en su inevitable presencia sino en el intento de sustraerlos a la crítica. Lo cual, dicho sea de paso, se observa con bastante frecuencia en algunos teóricos afines a tendencias "posmodernas: que proclaman la definitiva desaparición de todas las ideologías (menos de la propia, claro). Una "ética cristiana" que sea capaz de someter a revisión sus presupuestos no puede ser acusada a priori de tendenciosa, al menos no más que cualquier otra que escoja un determinado punto de partida -y siempre hay alguno- como sustrato de la rellexión filosófica. Un artículo, por ejemplo, como el de I. Gomez Caffarena acerca del concepto de persona en la ética teológica ${ }^{16}$ muestra un exquisito cuidado en delimitar el campo de la creencia religiosa del propio de la filosofía moral, de modo que su opción de creyente no resta radicalidad a la crítica.

Sin embargo, este equilibrio no siempre es fácil. Muchas veces el creyente se siente obligado a dialogar con una carga excesiva de presupuestos éticos, resultante de muchos siglos de teología moral y derecho canónico, que oscurecen su libertad de pensamiento y con- vierten su reflexión en incomprensible para el lector no iniciado en tales sutilezas; entre los artículos del libro que comentamos hay algunos temas en los que resuenan discusiones escolásticas tan alejadas de los supuestos de nuestra cultura que más que extraños nos resultan irrelevantes. Así, por ejemplo, largas disquisiciones acerca de la interpretación del magisterio de la Iglesia sobre la doctrina social o la sexualidad cuyo contenido ético se nos antoja de escasa entidad, en la medida en que sus condicionamientos ideológicos han sido largamente superados (sustituidos por otros, evidentemente) por muchos siglos de historia del pensamiento. En muchos de estos artículos se advierte, sin duda, un esfuerzo por dialogar con la cultura contemporánea, pero no podemos evitar la sensación de que algunos viejos temas (como el craso naturalismo escolástico, por ejemplo) tienen más valor como datos históricos que como interlocutores en una discusión actual. Decía Borges que la Teología era una rama de la literatura fantástica. Y lo decía sin ánimo de desvalorizar un género literario que estimaba profundamente. Quizás el aporte de una ética cristiana consista en explorar las posibilidades de una utopía que exige al pensamiento forzar sus limites para encontrar en el camino nuevas dimensiones de la experiencia moral; su riesgo, verse obligada a asumir como propia una historia que actúa en ocasiones como un lastre, dirigiendo la reflexión en direcciones carentes - para nosotros-de interés ético.

Nos hemos limitado a comentar, como decíamos al comienzo, algunos aspectos de unas pocas obras recientemente publicadas en España. En todas ellas valen más las tentativas que los resultados, como no podía dejar de suceder en una cultura en la que wel mundo de la vida» aparece igualmente perplejo. 
Si excluimos la altemativa -hoy muy socorrida- de sacralizar la confusión mediante un simplismo reduccionista, nos quedan estas (y otras) éticas cuyo mérito consiste en exigir del pensamiento lo que quizás no pueda ofrecernos pero que en todo caso merece ser buscado. O sea, seguir haciendo Filosoffa.

\section{NOTAS}

1. José Rubio Carracedo, Etica constructiva y autonomia personal, Madrid, Tecnos, 1992, p. 34 .

2. Javier Muguerza y otros, El fundamento de los derechos humanas, Madrid, Debate, 1989, p. 49.

3. Enrique Bonete, Arangurent la etica entre la religionn y la política, Madrid, Tecnos, 1989.

4. Ibid., p. 91.

5. Ibid, pp. 345-346.

6. Adela Cortina, Etica sin moral, Madrid, Tecnos, 1990.

7. Ibid, p. 177 .

B. Ib:d, p. 107.
9. Ver nota 1.

10. Rubio Carracedo, op. cit., pp. 151-152.

11. Bbid., p. 164.

12. Ver J. Muguerza, La altemativa del disenso, en $\}$. Muguerza y otros, citado en nota 2.

13. Ver A. Klappenbach, Etica y diferencias, Isegoria, 3 (abril 1991), pp. 186-195.

14. Marciano Vidal (ed.), Conceptos fundamentales de etica teologica, Madrid. Trotta, 1992.

15. Tbid., p. 10.

16. J. Gómez Caffarena, Persona y ética teológica, en M. Vidal (ed.), citado en nota 14. 